\title{
HELMINTHIC INFECTION IN DIGESTIVE SYSTEM OF GOATS IN SLAUGHTERHOUSE, MANFALOUT, ASSIUT GOVERNORATE, EGYPT By
}

AHMED G. ABDELAZEEM ${ }^{1}$, AHMED K. DYAB ${ }^{2^{*}}$ and YASSER M. MOHAMED ${ }^{2}$ Departments of Parasitology, Faculty of Veterinary Medicine, Aswan University ${ }^{1}$, Aswan Governorate and Faculty of Medicine, Assiut University ${ }^{2}$, Assiut Governorate, Egypt ( ${ }^{*}$ Correspondence:ahmedsaf2001@yahoo.com)

\section{Abstract}

A total of 90 goats digestive tracts were collected between May 2018 and end of September 2019 from private public abattoir in Beni-Adi (Manfalout) and examined for helminthes. They were Fasciola hepatica \& F. gigantica 40\%, Moniezia expansa (6.7\%), Avitellina centripunctata (6.7\%), Haemonchus spp. (16.7\%), Trichostrongylus axei (10\%), Ostertagia ostertagia (6.7\%), Oe-sophagostomum venulosum (10\%), Skrjabinema ovis $(10 \%)$ and 2 larval cestodes, Cysticercus tenuicollis (20\%), and hydatid cyst (6.7\%). Most of these parasites are zononosis.

Key words: Assiut Governorate, Slaughtered goats, helminthic infection.

\section{Introduction}

Goats are one of the most beneficial livestock. In Egypt, development of rural areas could be achieved depending on sheep and goat which is considered as one of the most promising animals to achieve the aims of meat production supplies for the human being (Sultan et al, 2010). They are one of the important sources of animal protein mainly in the Arabian Countries. Goats are used in ceremonial festivities throughout the country as well as production of cashmere and mohair fibers (Smith and Sherman, 1994). Such animals are a source of preparation of human and animal vaccines, manufacture of medical surgical threads from the small intestine and formation of manure fertilizers for soil from their fecal pellets (Mohammed, 2008). No doubt, parasitoses are risky for all domestic in terms of morbidity and mortality (Urquhart et al, 1996) as well as economic losses (Ensminger, 2002). Besides, unthrifty which included weight loss, low birth weights and difficulty in kidding due to zoonosis parasites causing morbidity and even mortality (Khalafahlla et al, 2011). Helminthiasis infections of goats are major factors for productivity reduction, and affected organs condemnation. Small-holders may not easily detect the effects of internal parasites on animals, because of the generally subclinical or chronic nature of the helminthic infections, So, the subclinical parasitic infections were responsible for significant economic loss, as once clinical disease occurred in edible animals due to productivity and meat processing (Kaplan, 2006). Some helminthes are zoonosis as hydatidosis, trichinosis and coenurosis (Wang et al, 2002). Thus, slaughtered animals must be examined for bacteria and parasites (Haridy et al, 2008) with eradication programs (Al-Qudah et al, 2008).

This work aimed to study the gasterointestinal parasites in slaughtered goats in Manfalout City, Assiut Governorate by postmortem macroscopic and microscopic examinations using simple and electron microscopic studies.

\section{Material and Methods}

Goats: A total 90 were examined for helminthic infection from the beginning of May 2018 to last September 2019, from private public abattoir in Beni-Adi village Manfalout City. Animals' age was identified by dental inspection, as young with temporary incisors (milk teeth) and adult with permanent incisors (Mekonnen, 2007).

Collection and examination: Body cavity of each goat carcasses was macroscopically examined as a routine abattoir post mortem. Liver was palpated and dissected for any parasites. Rumen and reticulum were examined after evacuating their contents to collect parasites. Abomasum, small and large intestines was ligated at both ends and safely carried directly to laboratory, Parasitology Department, Assiut Animal Health Research Institute. Each organ was opened with a scissor 
and examined macroscopically for adults and parasitic nodules. Their contents were washed separately through a 90-mesh sieve (large intestine through a 250-mesh sieve), put in a clean bucket and allowed to stand for about one hour to allow sedimentation of worms. After that, the supernatant was discarded and the bucket was filled with water again for washing. The process of washing was repeated till the supernatant became clear. The sediments were carefully examined by the naked eyes as well as a hand lens, then diluted and examined under a stereomicroscope (Umur and Yukari, 2005).

Preparation: Worms were washed several times in normal physiological saline, and kept overnight in refrigerator for complete relaxation. Worms were flattened between two slides and placed in the fixative $(10 \%$ formalin) for $24 \mathrm{hrs}$. The fixed worms were washed several times in running tape water to remove the traces of formalin (Soulsby, 1988). Cestodes and trematodes were stained with acetic acid- alum carmine. Formula: Carmine 2gm, Acetic acid 25ml, Potassium alum $6 \mathrm{gm} \&$ Distilled water $100 \mathrm{ml}$. The dye and alum were boiled in water; $1 \mathrm{hr}$ cooled, acid added, left for ten days for ripening and then filtered.

Staining and mounting: Fixed specimens were left to stain overnight. Stained specimens were washed several times with distilled water. Differentiation of the over-stained specimens was done in acidified $70 \%$ ethanol. Specimens were examined under dissecting microscope until they were well dif-

ferentiated, and wash several times in $70 \%$ ethanol to remove residual $\mathrm{HCl}$. Dehydration was done in ascending ethanol grades and absolute ethanol for 30 minutes in each change. Stained specimens were cleared in clove oil for few minutes, mounted in Canada balsam and left to dry in an oven at $37^{\circ} \mathrm{C}$.

Fixation and preservation: The nematodes were immersed in warm $70 \%$ ethanol $\left(60^{\circ} \mathrm{C}\right)$ and preserved in $70 \%$ ethanol with $5 \%$ glycerin. They were cleared in lactophenol for 24hrs (Watson, 1960) consisted of Glycerol $(10.6 \mathrm{ml})$, melted phenol $(10 \mathrm{ml})$, Lactic acid $(8.2 \mathrm{ml})$, distilled water $(10 \mathrm{ml})$, mounted in glycerin jelly [Gelatin granulated $(10 \mathrm{ml})$, distilled water $(60 \mathrm{ml})$, Glycerin $(70 \mathrm{ml})$, melted phenol $(0.5 \mathrm{ml})]$. in small wide mouth bottles in refrigerator until needed use, to liquefy put in water bath at $56^{\circ} \mathrm{C}$,

\section{Results}

Post mortem examination: The digestive tracts were collected from May 2018 to the end of September 2019 from private public abattoir in Beni-Adi for helminthiasis. Species of helminthes in the digestive tract were Fasciola spp., Moniezia expansa, Avitellina centripunctata, Haemonchus spp., Trichostrongylus axei, Ostertagia ostertagia, Oesophagostomum venulosum, Skrjabinema ovis and two larval cestodes; Cysticercus tenuicollis and hydatid cyst. Both genus and species were identified according to the morphological characteristics using the valid taxonomic keys.

Details were given in table (1) and figures

\section{(1 to 25$)$.}

Table 1: Prevalence of parasitic infection in 90 goats in post mortem examination.

\begin{tabular}{|c|c|c|c|}
\hline Parasite recovered & Site & No. Infected & $\%$ \\
\hline Trematodes: Fasciola spp. & bile ducts of liver & 36 & 40 \\
\hline Cestodes: Moniezia expansa & Small intestine & 6 & 6.7 \\
Avitellina centripunctata & Small intestine & 6 & 6.7 \\
Cysticercus tenuicollis & Mesentery and liver & 18 & 20 \\
Hydatid cyst. & Liver & 6 & 6.7 \\
\hline Nematodes: Haemonchus spp. & Abomasum & 48 & 53.3 \\
Trichostrongylus axei & Abomasum & 15 & 16.7 \\
Ostertagia ostertagia & Abomasum & 9 & 10 \\
O. venulosum & Large intestine & 6 & 6.7 \\
Skrjabinema ovis & Colon and Caecum & 9 & 10 \\
\hline
\end{tabular}

Discussion

In the present study, Fasciola spp. were in higher prevalence $40 \%$ than given by Ba- yu et al. (2013) in Ethiopia found (2.26\%), Elshahawy et al. (2014) in Upper Egypt reported $F$. gigantica in (4.4\%), Ezatpour et 
al. (2015) in Iran reported 3.9\%, ElKhtam and Khalafalla (2016) in Sadat City (Egypt) reported $F$. hepatica $(0.41 \%)$, and $F$. gigantica $(5.83 \%)$, as well as the role of donkeys and horses as zoonotic fascioliasis (Haridy et al, 2002) and high rate of Egyptian human fascioliasis were reported (Abo-Madyan et $a l, 2004)$. Variable in prevalence rates might be due to climatic variations, habitats, samples number, veterinarians follow-up and periodical control measures (Berhe et al, 2009), added by ecological factors favoring snail hosts (Chanie and Begashaw, 2012).

In Assiut Governorate the high infection rate might the old-aged slaughtered animals subjected to several exposures to infections or development of fasciolicidal resistance. This agreed with Khan et al. (2009) who found that high fascioliasis rate was due to improper control of animal fascialiasis and its snail hosts, as well as the opened drainage system.

In the present study, Moniezia expansa showed a rate of $6.7 \%$. This was lower than $20 \%$ in Iceland (Kristmundsson and Richter, 2000), 17.04\% in India (Pathak and Pal, 2008), 53\% in Eastern Ethiopia (Sissay et al, 2008 ), and $18.3 \%$ in Giza Governorate (Hassan et al, 2019) but, higher than $0.1 \%$ in Darfur, Sudan (Almalaik et al. 2008). Also, El Shazly et al. (2004) in Dakahlia G. reported one zoonotic monisziasis.

In the present study, Avitellina centeripunctata showed a rate of $6.7 \%$, which was higher than $3.40 \%$ in India (Pathak and $\mathrm{Pal}$, 2008), but lower than $21 \%$ in Ethiopia (Sissay et al, 2008).

In the present study, Cysticercus tenuicollis showed a rate of $20 \%$. This went with $18.04 \%$ in Iran (Radfar et al, 2005), but lower than 53\% in Ethiopia (Sissay et al, 2008), $6.86 \%$ Assiut Governorate (Arafa and Fouad, 2008), 24.2\% in Aswan G. (Dyab et al, 2017). But, Soliman and Taha (2012) in AlMadinah, Saudi Arabia reported 1.8\%. Variation in infection rates with this larval stage may be attributed to abundance of its host, stray dogs in sheep and goats farms (Kilinc et al, 2019).

In the present study, hydatid cyst, larval of E. granulosus was detected in $6.7 \%$ of livers. This was higher than $2.57 \%$ in Ahwaz, Iran (Ahmadi and Meshkehkar, 2011), 0.16\% in Al-Madinah, Saudi Arabia (Soliman and Taha, 2012), $1.39 \%$ in Addis Ababa, Ethio pia (Bayu et al, 2013) \& $2.46 \%$ in El-Kharga, Egypt (Osman et al. (2014). But, the incidence was lower than $65 \%$ in eastern Ethiopia (Sissay et al, 2008), 10\% in Shiraz, Iran (Oryan et al, 2012) and 10.7\% in India (Moudgil et al, 2020). This variation may be due to genetic factors and immunity that affected infection susceptibility. But, zoonotic hydatidosis was a silent health problem (El-Shazly et al, 2007). Egyptian echinococcosis/ hydatidosis was reported in stray dogs (Sabry et al, 2012), edible animals (Haridy et al, 2000) and man (Mazyad et al, 1998; El-Sayed et al, 2020)

In the present study, nematodes prevalence was $53.3 \%$. This more or less went with 43.8\% in Saudi Arabia (El-Azazy, 1995), $52 \%$ in Nigeria (Nwosu et al, 2007), 54.3\% in Kashmir (Tariq et al, 2010), but less than 93\% in central Spain (Valcárcel and García Romero, 1999), and 83\% in Sanliurfa, Turkey (Altaş et al, 2009). In general, these gastrointestinal nematodes remain one of the main constraints to ruminant production, caused reduction in skeletal growth, live-weight gain in milk yield and could affect the control strategies (van Houtert and Sykes, 2010), but expression of immune responses against them were less efficient in goats than sheep (Zanzani et al, 2014). The anthelmintic resistance phenomenon spread in many countries with differences in prevalence and developed rapid resistance in goats (Di Cerbo et al, 2010). Genera, Haemonchus, and Trichostrongylus were proved to be zoonosis (Bowman, 2020), and now what about other gastrointestinal nematodes of goats?

\section{Conclusion}

Approximately one-sixth of the worlds' population is infected with helminths and this class of parasite play a zoonosis major role 
in the domestic livestock.

The intestinal helminths alter the intestinal physiology, permeability, mucous secretion and the antimicrobial peptides production, which may impact on bacterial survival and spatial organization. Consequently, the early diagnosis and the proper treatment of domestic animals is a must for human welfare.

The composition knowledge of the goats' gastrointestinal helminthic fauna of and their epidemiological parameters is a must to prevent the anthelminthic resistance.

\section{References}

Abo-Madyan, AA, Morsy, TA, Motawea, SM, Morsy, ATA, 2004: Clinical trial of Mirazid ${ }^{\circledR}$ in treatment of human fascioliasis in Ezbet ElBakly (Tamyia Center) Al-Fayoum Governorate. J. Egypt Soc. Parasitol. 34, 3:807-18.

Ahmadi, NA, Meshkehkar, M, 2011: An abattoir-based study on the prevalence and economic losses due to cystic echinococcosis in slaughtered herbivores in Ahwaz, south-western Iran. J. Helminthol. 85, 1:33-9.

Almalaik, AHA, Bashar, AE, Abakar, AD, 2008: Prevalence and dynamics of some gastrointestinal parasites of sheep and goats in tulus area based on post-mortem examination. Asian J. Anim. Vet. Adv. 3, 6:390-9.

Al-Qudah, KM, Al-Majali, AM, Obaidat, M M, 2008: A study on pathological and microbiological conditions in goats in slaughter houses in Jordan. Asian J. Anim. Vet. Adv. 3, 4:269-74.

Arafa, MI, Fouad, IA, 2008: Studies on some internal parasites of goats in Assiut Governorate especially which affecting liver. Ass. Univ. Bull. Environ. Res. 11, 1:57-71.

Bayu, Y, Asmelash, A, Zerom, K, Ayalew, T, 2013: Prevalence and economic importance of liver parasites: Hydatid cyst, Fasciola species and Cysticercus tenuicolis in sheep and goats slaughtered at Addis Ababa abattoir enterprise in Ethiopia. J. Vet. Med. Anim. Hlth. 5, 1:1-7.

Berhe, G, Berhane, K, Tadesse, G, 2009: Prevalence and economic significance of fasciolosis in cattle in mekelle area of Ethiopia. Trop. Anim. Hlth. Prod. 41, 7:1503-4.

Bowman, DD, 2020: Georgis' Parasitology for Veterinarians E-Book, Elsevier Health Sciences.

Chanie, M, Begashaw, S, 2012: Assessment of the economic impact and prevalence of ovine fasciolosis in Menz Lalo Midir District, North- east Ethiopia. Vet. World 5, 5:261-4.

Di Cerbo, AR, Manfredi, MT, Zanzani, S, Stradiotto, K, 2010: Gastrointestinal infection in goat far$\mathrm{ms}$ in Lombardy (Northern Italy): Analysis on community and spatial distribution of parasites. Small Rum. Res. 88:102-12.

Dyab, AK, Marghany, ME, Osman, RA, Ahmed, MA, 2017: Cysticercosis in small ruminants slaughtered in Aswan slaughterhouse, Egypt. Assiut Vet. Med. J. 63, 155:1-8.

El-Azazy, OM, 1995: Seasonal changes and inhibited development of the abomasal nematodes of sheep and goats in Saudi Arabia. Vet. Parasitol. 58, 1/2:91-8.

El-Sayed, YA, Ibrahim, EA, Morsy, TA, 2020: Peri-cystectomy versus cystotomy and enucleation of germinal layer by tissue spearing technique for lung hydatid in Egypt. J. Egypt. Soc. Parasitol. 50, 3:494-503.

EIKhtam AO, Khalafalla RE, 2016: Surveillance of helminthes and molecular phylogeny of Fasciola gigantica infecting goats in Sadat District, Egypt. Int. J. Sci. Res. Sci. Tech. 2, 4:18892.

Elshahawy, LS, Metwally, AM, Ibrahim, DA, 2014: An abattoir-based study on helminthes of slaughtered goats (Capra hircus L., 1758) in Upper Egypt, Egypt. Helminthol. 51, 1:67-72.

EI Shazly, AM, Morsy, TA, Dawod, HA, 2004: Human monisziasis expansa: The first Egyptian parasitic zoonosis. J. Egypt. Soc. Parasitol. 34, 2:515-8.

EI-Shazly, AM, Awad, SE, Nagaty, IM, Morsy, TA, 2007a: Echinoccosis in dogs in urban and rural areas ion Dakahlia Governorate, Egypt. J. Egypt. Soc. Parasitol. 37, 2:483-92.

El-Shazly, AM, Awad, SE, Hegazy, MA, Mohammad, KhA, Morsy, TA, 2007b: Echinococcosis granulosus/hydatidosis an endemic zoonotic disease in Egypt. J. Egypt. Soc. Parasitol. 37, 2:609-22.

Ensminger, MH, 2002: Sheep and Goat Science. $6^{\text {th }}$ ed. Interstate Publishers, Inc., Danville.

Ezatpour, B, Hasanvand, A, Azami, M, et al, 2015: Prevalence of liver fluke infections in slaughtered animals in Lorestan, Iran. J. Parasit. Dis. 39, 4:725-9.

Haridy, FM, Ibrahim, BB, Morsy, TA, 2000: Sheep-dog-man: The risk zoonotic cycle in hydatidosis. J. Egypt. Soc. Parasitol. 30, 2:423-9.

Haridy, FM, Abou Holw, SA, Hassan, AA, Morsy, TA, 2008: Cystic hydatidosis: A zoonotic silent health problem. J. Egypt. Soc. Parasi- 
tol. $38,2: 635-44$.

Haridy, FM, Morsy, TA, Gawish, NI, Antonios, SN, Abdel Gawad, AE, 2002: The potential role of donkeys and horses in zoonotic fascioliasis in Gharbia Governorate, Egypt. J. Egypt. Soc. Parasitol. 32, 2:561-70.

Hassan, NMF, Farag, TK, Abu Elezz, NMT, Abou-Zeina, HAA, 2019: Prevalence assessment of gastro-intestinal parasitic infections among goats in Giza Governorate, Egypt. Bull. Nat. Res. Cen. 43: 127

Kaplan, M, 2006: Update on parasite control in small ruminants: Addressing the challenges posed by multiple-drug resistant worms. Proc. Am. Assoc. Bovine Practitioners, Saint Paul, USA, September, 21-23.

Khalafalla, RE, Elsiefy, MA, Elbahy, NM, 2011: Seasonal prevalence of gastrointestinal nematode parasites of sheep in Northern region of Nile Delta, Egypt. Parasit. Dis. 108:337-40. Khan, MK, Sajid, MS, Khan, MN, Iqbal, Z, Iqbal, MU, 2009: Bovine fasciolosis: prevalence, eff-ects of treatment on productivity and cost benefit analysis in five districts of Punjab, Pakistan. Res. Vet. Sci. 87, 1:70 -5.

Kilinc, SG, Kesik, HK, Simsek, S, 2019: Molecular characterization and haplotypes of sheep and goat isolates of Cysticercus tenuicollis in Turkey. Parasitology 146, 8:1047-54

Kristmundsson, A, Richter, SH, 2000: Lung and gastrointestinal helminths of goats (Capra hircus) in Iceland Institute for Experimental Pathology, University of Iceland. Agri. Sci. 13:7985 .

Mazyad, MAM, Mostafa, MM, Morsy, TA, 1998: Spinal cord hydatid cysts in Egypt. J. Egypt. Soc. Parasitol. 28, 3:655-8

Moudgil, AD, Moudgil, P, Asrani RK, Agnihotri, RK, 2020: Hydatidosis in slaughtered sheep and goats in India: Prevalence, genotypic characterization and pathological studies. J. Helminthol. 94, 27: e1-5.

Nwosu, CO, Madu, PP, Richards, WS, 2007: Prevalence and seasonal changes in the population of gastrointestinal nematodes of small ruminants in the semi-arid zone of north-eastern $\mathrm{Ni}$ geria. Vet. Parasitol. 144, 1/2:118-24.

Oryan, A, Goorgipour, S, Moazeni, M, Shirian, S, 2012: Abattoir prevalence, organ distribution, public health and economic importance of major meta-cestodes in sheep, goats and cattle in the Fars, Southern Iran. Trop. Biomed. 29, 3: 349- 59.
Osman, FA, Mohamad, MG, Gadee, HI, 2014: The prevalence and biochemical characters of hydatid cyst in sheep and goats slaughtered at El-Karhga, New-Valley Governorate, Egypt. Sky J. Agric. Res. 3, 1:17-24.

Pathak, AK, Pal, S, 2008: Seasonal prevalence of GIT parasites in goats from drug district of Chattissgarh, India. Orig. Res. Vet. World 1, 5: 136-7.

Radfar, MH, Tajalli, S, Jalalzadeh, M, 2005: Prevalence and morphological characterization of Cysticercus tenuicollis (Taenia hydatigena cysticerci) from sheep and goats in Iran. Vet. Arh. 75:469-76.

Sabry, AA, Morsy, ATA, Morsy, TA, 2012: Zoonoses from dogs with special reference to Egypt. J. Egypt. Soc. Parasitol. 42, 3:583-604.

Sissay, MM, Uggla, A, Waller, PJ, 2008: Prevalence and seasonal incidence of larval and adult cestode infections of sheep and goats in Eastern Ethiopia. J. Trop. Anim. Hlth. Prod. 40, 6:38794.

Smith, MC, Sherman, DM, 1994: Goat Medicine. $1^{\text {st }}$ Edition, Lea \& Febiger, USA.

Soulsby, EJL, 1988: Helminths, Arthropods and Protozoa of Domesticated Animals English Language Book Society/Bailliere Tindall.

Soliman, MI, Taha, HA, 2012: Prevalence of three liver parasites in sheep and goats in AlMadinah Almunawwarah, Suadi Arabia Kingdom. J. Egypt. Soc. Parasitol. 42, 2:475-82.

Sultan, K, Desouky, AY, Elseify, MA, Elbahy, NM, 2010: An abattoir study on the prevalence of some gastrointestinal helminths in Gharbia Governor- ate, Egypt. Glob. Vet. 5, 2:84-7.

Tariq, KA, Chishti, MZ, Ahmad, F, 2010: Gastrointestinal nematode infections in goats relative to season, host sex and age from the Kashmir valley, India. J. Helminthol. 84, 1:93-7.

Thomas, N, Teshale, S, Kumsa, B, 2007: Abomasal nematodes of sheep and goats slaughtered in Awassa (Ethiopia): Species composition, prevalence and vulvar morphology. Helminthol. 44, 2:70-5.

Umur, S, Yukari, BA, 2005: An abattoir survey of gastrointestinal nematodes in sheep in bordure region, Turkey. Turk. J. Vet. Anim. Sci. 29: 1195-201.

Valcárcel, F, García Romero, C, 1999: Prevalence and seasonal pattern of caprine trichostrongyles in a dry area of central Spain. J. Vet. Med. B. 46. 10:673-81.

van Houtert, MF, Sykes, AR, 2010: Implicati- 
ons of nutrition for the ability of ruminants to withstand gastrointestinal nematode infections. Int. J. Parasitol. 26:1151-67.

Wang, H, Chai, JJ, Liu, FJ, Jiang, L, Jiao, W, et al, 2002: A study on ecological epidemiology of two hydatid diseases in Qinghai, Chin. J. Parasit. Dis. Con. 15, 5:284-6.

Waston, JM, 1960: Medical Helminthology $1^{\text {st }}$ ed. Bailliere Tindall and Cox, London.
Urquhart, GM, Armour, J, Duncan, JL, Dunn, AM, Jennings, FW, 1996: Veterinary Parasitology, $2^{\text {nd }}$ ed. Blackwell Science, the United Kingdom.

Zanzani, SA, Gazzonis, AL, Cerbo, DA, Varady, M, Manfredi, MT, 2014: Gastrointestinal nematodes of dairy goats, anthelmintic resistance and practices of parasite control in Northern Italy. BMC Vet. Res. 10:114

Fig. 1: Adult Fasciola spp. in bile duct

\section{Explanation of figures}

Fig. 2: Fasciola hepatica showed oral and ventral sucker, vitelline glands (arrows) .

Fig. 3: Fasciola gigantica adult worm,with branched intestinal ceca.

Fig. 4: Cysticercus tenuicollis attached to liver.

Fig. 5: Hydatid cyst in liver.

Fig. 6: Moniezia expansa adult worm.

Fig. 7: Moniezia expansa mature segments showed double set of genital organs and intersegmental glands

Fig. 8: Avitellina centripunctata adult.

Fig. 9: Avitellina centripunctata gravid segments showed par-uterine organ.

Fig. 10: Trichostrongylus axei anterior end showed excretory notch.

Fig. 11: Trichostrongylus axei female caudal end showed vulvar region.

Fig. 12: Trichostrongylus axei male caudal end showed bursa, unequal spicules and gubernaculum.

Fig. 13: Oesophagostomum venulosum anterior end showed buccal capsule, cephalic vesicle, cervical groove \& oesophagus.

Fig. 14: Oesophagostomum venulosum female caudal end showed anal pore.

Fig. 15: Skrjabinema ovis anterior end showed characteristic oesophagus with a large posterior bulb.

Fig. 16: Skrjabinema ovis female, tapered tail and anal pore.

Fig. 17: Skrjabinema ovis male caudal end characteristic spicule.

Fig. 18: Ostertagia ostertagia anterior end showed cervical papillae.

Fig. 19: Ostertagia ostertagia female posterior end showed anal pore.

Fig. 20: Ostertagia ostertagia male showed copulatory bursa, spicule.

Fig. 21: Haemonchus spp. adult.

Fig. 22: Anterior end of Haemonchus contortus showed buccal capsule with a lancet.

Fig. 23: Anterior end of Haemonchus contortus showing cervical papillae like spine.

Fig. 24: Haemonchus contortus female vulvar region showed thumb-like vulvar flap

Fig. 25: Posterior end of Haemonchus contortus male showed copulatory bursa

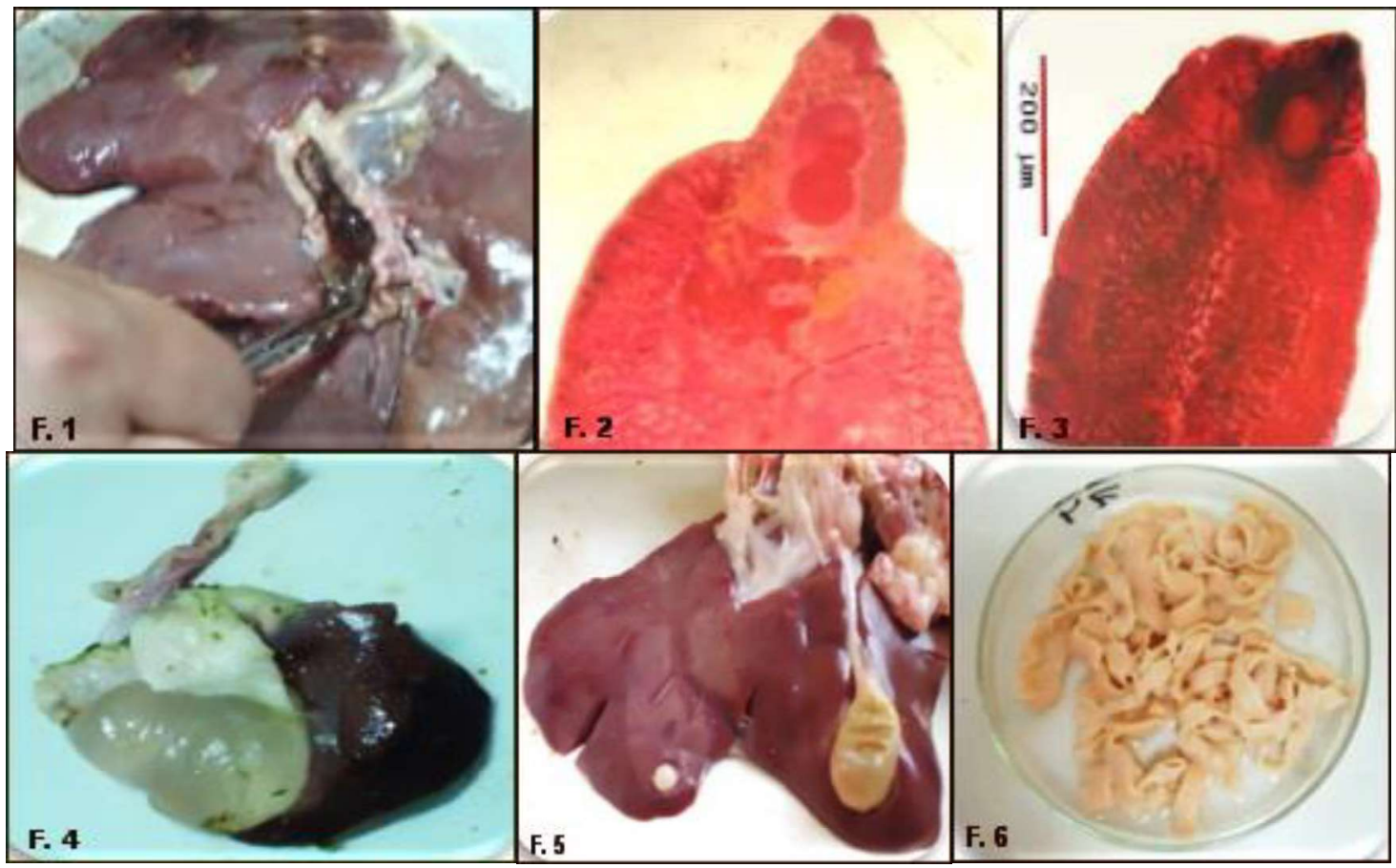



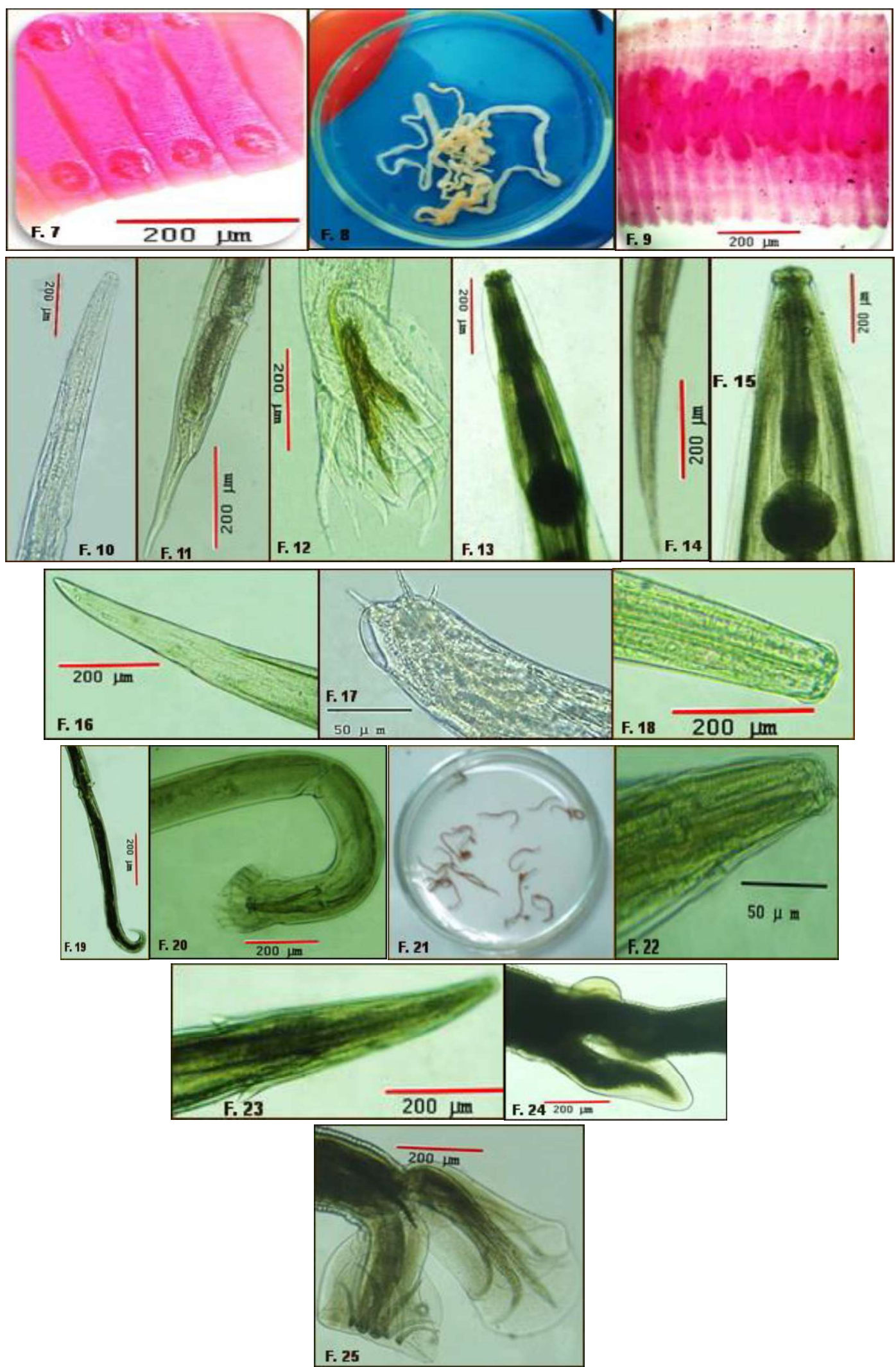